\title{
Investigation of the Exergy Analysis and Efficiency in the Turning of DIN 1.2367 Material
}

\author{
Ali Kemal ÇAKIR* \\ Department of Machinery and Metal Technologies, Aydın Vocational School, Adnan Menderes University, PK 09100, Center, \\ Aydin, Turkey.
}

\section{Keywords}

Exergy Analysis,

Efficiency,

Energy,

Turning,

DIN 1.2367.

\begin{abstract}
Increases of product in manufacturing processes have made its impact felt in Turning, one of the important branches of the industry. Increases in manufacturing also increase energy consumption. We can achieve this with efficiency studies in energy consumption. Energy efficiency studies to be carried out will reduce carbon emissions that will be revealed in turning processes and harm the environment. There are many studies on optimization of cutting parameters in turning processes. However, there are few studies on the effect of optimization of cutting parameters on energy efficiency and carbon emission values. This study has been trying to resolve this tartness. In the study, the efficiency calculation was made by extracting the exergy values of the processes of turning DIN 1.2367 steel material. In addition, processes in turning other metals can be determined and exergy calculations and efficiency values of these processes can be derived.
\end{abstract}

\section{Introduction}

For Consumption of natural resources and increasing dirty in industrial processes have led to an increase in environmental problems. Environmental concerns need to be addressed. Addressing these concerns includes increased pressure of political and effected regulations for both producer and end users. Admitting sustainable production ideas offers us a way to improve the industry's economic, impacts of environmental, and performance of social [1].

The increase in the world population has also increased the demand for industrial processes. The increase in demand for industrial processes has also caused an increase in manufacturing processes. Increasing manufacturing processes have also caused an increase in both economic costs and energy consumption values. The increase in energy consumption increases the initial investment, therefore the operating and maintenance expenses, thus increasing the economic costs [2].

These increases in manufacturing processes have made its impact felt in Turning, one of the important branches of the industry. In turning processes, their costs must be economical as well as obtaining a good surface. We can achieve this with efficiency studies in energy consumption. Energy efficiency studies to be carried out will reduce carbon emissions that will be revealed in turning processes and harm the environment. Therefore, these will be both economical and environmentally friendly.

We can start energy efficiency studies in turning by choosing the cutting parameters at optimum values. Because cutting parameters that are not well-adjusted cause an increase in costs in turning processes. It also has a negative impact on the environment due to the increase in carbon emissions. In order to reduce carbon emissions resulting from energy production, the energy used in production must be reduced. In the literature, energy consumed for non-cutting processes dominates the total energy consumption in machining [3].

Efficiency in manufacturing processes can be achieved by reducing or minimizing environmental impact rates in production processes. Energy and environmental analysis of the processes in production, especially in the manufacturing sector, has been done by several researchers [4-7]. In addition, some researchers worked on cost analysis in manufacturing processes [8, 9]. Also, Rajemi at al., 2010 [10] studied on the calculation of minimum energy quantities at optimum cutting conditions.

There are many studies on optimization of cutting parameters in turning processes. However, there are few studies on the effect of optimization of cutting parameters on energy efficiency and carbon emission values. In addition, there is much less work on determining the processes in turning processes and finding the exergy values of these processes and their effect on productivity. This study has been trying to resolve this tartness. In the study, the efficiency calculation was made by extracting the exergy values of the processes of turning DIN 1.2367 steel material. In addition, processes in turning other metals can be determined and exergy calculations and efficiency values of these processes can be derived. In the study, it was developed calculation methodologies about exergy, the exergy calculation in turning DIN 1.2367 steel material was made by using the exergy equations in the work of Rajemi et al. 2009 [3] and Ghandehariun, A. et al., 2015 [4]. The effect of cutting parameters in the turning process was examined, especially the effect of cutting speed on exergy was emphasized.

\subsection{Minimizing Energy Requirements}

In order to keep the energy requirement in the turning process to a minimum, some processes need to be determined. These can be listed as installation process, cutting operations, tool change, cutting tool production and producing workpiece material. After the determination of these processes, the total energy value used in the dry turning process, the energy values of these processes (energy consumed by the machine during the setup process, cutting processes and tool change, energy consumed to produce a cutting tool and energy spent to produce a workpiece material) is found with their using.

The workpiece material used in the turning process is not taken into account in the turning process as it has a fixed value for each product. Because it does not affect the optimization process in the turning process. Also, it is not every time likely to decrease the concrete energy of the workpiece material. So, it is not considered in the 
evaluation of energy consumption [10]. The total energy (W) consumed in a dry turning process is obtained using the Eq. (1).

$W=W_{\text {setup }}+W_{\text {machinig }}+W_{\text {tool change }}+E_{\text {tool }}$

$\mathrm{W}_{\text {setup }}$ is the energy that the machine consumes when setting up the setup. $W_{\text {machinig }}$ is the energy needed during dry turning and is derived from the energy consumed to power the machine modules and the energy consumed for machining. $\mathrm{W}_{\text {tool }}$ change is the energy consumed during tool change [4].

The power during tool change equals the power consumption of the machine at idle because the tool is usually changed while the spindle is turned off. $E_{\text {tool }}$ is the energy footprint of the cutting tool and can be calculated from the product of the energy per cutting edge. The number of cutting edges required to complete the transition to cutting edge machining [4]. From the calculation formulas mentioned above, Equation (2) can be written. Equation (2) expresses the minimum energy requirement used in the dry turning process.

$W=\dot{W}_{0} t_{\text {setup }}+\left(\dot{W}_{0}+k \dot{V}\right) t_{\text {cutting }}+\dot{W}_{0} t_{\text {tool change }}\left(\frac{t_{\text {cutting }}}{t}\right)+$

$E_{\text {cutting edge }}\left(\frac{t_{\text {cutting }}}{t}\right)$

$\dot{W}_{0}$ used here is the machine modules' power consumed. (i.e., the power consumption of the machine during without cutting operations). $\mathrm{k}$ is the specific energy demand in dry cutting processes and $\dot{V}$ is the removal rate of material. $t_{\text {setup }}, t_{\text {cutting }}$ and $t_{\text {tool change }}$ are machine setup time, cutting time and tool change time, respectively. $t$ indicates the life of the cutting tool. In dry turning processes, the tool life equation is obtained using Equation (3), [10].

$t=\frac{A}{V c^{1 / \alpha} f^{1 / \beta}}$

$V_{c}$ used in Eq. (3) is the speed of cutting, $f$ is the feedrate. $\alpha$ and $\beta$ are the speed of cutting and feedrate exponents in the tool life equation, seriatim. Also, A's value is a constant that can be found using experimental data.

Time of cutting in dry turning process can be evaluated with the equation (4), [4].

$t_{\text {cutting }}=\frac{\pi D_{\text {avg }} l}{f V_{c}}$

1 used in Eq. (4) is the cutting length, and Davg is the average workpiece diameter calculated from the starting and final diameters of the workpiece, $D_{i}$ and $D_{f}$.

We can express the time of cutting and tool life stated above with the energy equation by Eq. (5).

$W=\dot{W}_{0} t_{\text {setup }}+\frac{\dot{W}_{0} \pi D_{\text {avg }} l}{f v_{c}}+\frac{k \pi l}{4}\left(D_{i}^{2}-D_{f}^{2}\right)+$

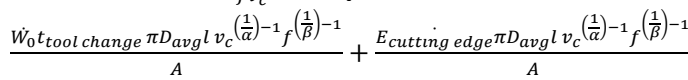

By using equation (5), we can find the optimum tool life. In this way, energy consumption in the process can be minimized. This tool life value can then be used in the tool life equation to obtain the optimum cutting speed for minimal energy machining.

Optimization of the turning process is obtained by finding the minimum point for the model duty seen in equation (5). It can be found by deriving the derivative of the total energy with respect to the cutting speed and equating it to zero for the model [4]. So, we can find the minimum point. This situation is shown in Equation (6).

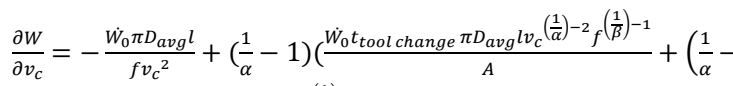

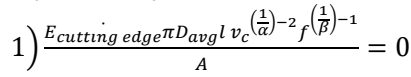

Equation (6) can be simplified by Equation (7).

$\frac{A}{f^{1 / \beta} v_{c}^{1 / \alpha}}=\left(\frac{1}{\alpha}-1\right)\left(\frac{\dot{W}_{0} t_{\text {tool change }}+E_{\text {cutting edge }}}{\dot{W}_{0}}\right)$

Equation (8) is obtained using Taylor's $[4,10,11]$ tool life equation. $t_{\text {opt }, E n}=\left(\frac{1}{\alpha}-1\right)\left(\frac{\dot{W}_{0} t_{\text {tool change }}+E_{\text {cutting edge }}}{\dot{W}_{0}}\right)$

Equation (8) shows that the main factors in achieving minimum energy consumption are tool life speed exponent, power consumption of machine modules, tool change time and energy footprint for cutting tools. Also, Equation (8) will be used to obtain optimum tool life for minimal energy use during machining.

\subsection{Minimum Exergy Loss}

The exergy balance equation can be written as follows for dry turning [12].

$E x_{i n}+E x_{w, \text { in }}+E x_{Q, \text { in }}=E x_{o u t}+E x_{w, o u t}+E x_{Q, o u t}+E x_{\text {loss }}$

Exin, Exout in Eq. (9), are mass exergy for input and output. The output exergy is zero as the output materials are supposed to be in the similar thermodynamic state as the ambient (state of dead). $\mathbf{E x}_{\mathrm{w}, \text { in }}$ and $\mathbf{E x}_{\mathrm{w}, \text { out }}$ symbolize the work' exergies and they are equal to the system's work input and output, seriatim. The output of work in the turning process is equal zero since there is no effect on the machining. The loss exergy is shown by $\mathrm{Ex}_{\mathrm{loss}} . \mathrm{Ex}_{\mathrm{Q}, \mathrm{in}}$ and $\mathrm{Ex}_{\mathrm{Q}, \text { out }}$ are heat exergies at the inlet and outlet in machining. The input of heat and incorporated heat exergy for the processing process is zero [4]. Because there is no change in environmental conditions. The heat exergy output in the processing process has a different value. Because the heat value coming out of the system is different from environmental conditions. The heat exergy output can be calculated using equation (10) in the machining process.

$\mathrm{Ex}_{\mathrm{Q}, \text { out }}=\mathrm{Q}_{\text {out }}\left(1-\mathrm{T}_{0} / \mathrm{T}\right)$

Qout show out of heat in system of machining. $T_{0}$ is temperature of ambient. $\mathrm{T}$ is the temperature of the turning process. Input of work in turning process is equal to energy consumption for electrical and Eq. (11) shows it.

$\mathrm{W}_{\text {elec }}=\mathrm{W}_{\text {setup }}+\mathrm{W}_{\text {machining }}+\mathrm{W}_{\text {tool change }}$

Used here, $\mathrm{W}_{\text {setup }}, \mathrm{W}_{\text {machining }}$ and $\mathrm{W}_{\text {tool change, }}$ are energy consumption through set-up time, time of cutting and time of tool change, seriatim. Consumption of energy in turning process is founded using Eq. (12), $[4,13]$.

$\mathrm{W}_{\text {machining }}=\left(\dot{W}_{0}+k \dot{V}\right) t_{\text {cutting }}$

The consumption of energy through the tool change period is derived from the machine's idle consumption of power and the product of the time needed to change the tool. So, the input exergy for work is expressed by Eq. (13).

$E x_{w, \text { in }}=W_{\text {elec }}=\dot{W}_{o} t_{\text {setup }}+\left(\dot{W}_{o}+k \dot{V}\right) t_{\text {cutting }}+\dot{W}_{o} t_{\text {tool change }}\left(\frac{t_{\text {cutting }}}{t}\right)$

By using the values defined for Equation (3) and Equation (4), the work exergy input in the machining process can be explained with Equation (14).

$E x_{w, \text { in }}=W_{\text {elec }}=\dot{W}_{o} t_{\text {setup }}+\left(\dot{W}_{o} \frac{\pi D_{\text {avg }} l}{f v_{c}}+\frac{k \pi l\left(D_{i}{ }^{2}-D_{f}{ }^{2}\right.}{4}\right)+$

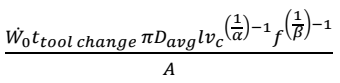

Input exergy of machining can be expressed in Eq. (15).

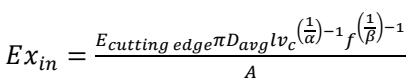

Power consumption of idle in machine lathe is generally spread as heat. So, output of the heat can be accepted to be equal Power consumption of idle in machine lathe using by Eq. (16).

$Q=\dot{W}_{o}\left(t_{\text {setup }}+\frac{\pi D_{\text {avg }} l}{f v_{c}}+\frac{t_{\text {tool change }} \pi D_{\text {avg }} v_{c}\left(\frac{1}{\alpha}\right)-1}{A} f^{\left(\frac{1}{\beta}\right)-1}\right)$

In summary, Eq. (17) can be written as follows to calculate the exergy loss in dry turning process [4]. 


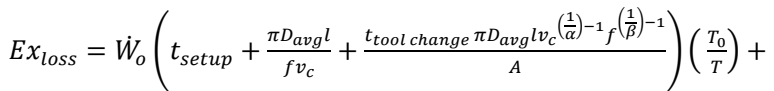

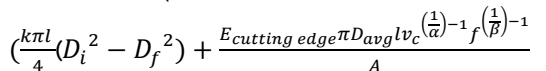

Tool life is an important parameter for turning processes. Value of tool life is stated in the equation of tool life to get the optimum speed of cutting. The goal of tool life optimization is to achieve an optimum tool life that meets the minimum exergy loss criteria. We can find this by minimizing the model presented in equation (17). We can find this by minimizing the model presented in equation (17). In this, we can take the derivative of the function to equal zero $[4,10]$

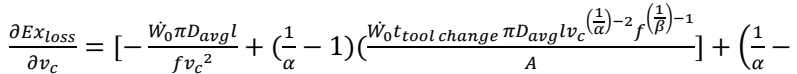

1) $\frac{E_{\text {cutting edge } \pi D_{\text {avg }} l v_{c}\left(\frac{1}{\alpha}\right)-2} f^{\left(\frac{1}{\beta}\right)-1}}{A}=0$

$\Rightarrow \frac{A}{v_{c}\left(\frac{1}{\alpha}\right)_{f}^{\left(\frac{1}{\beta}\right)}}=\left(\frac{1}{\alpha}-1\right) \frac{\dot{W}_{0} t_{\text {tool change }}+E_{\text {cutting edge }}\left(\frac{T}{T_{0}}\right)}{\dot{W}_{0}}$

It can obtain Eq. (20) by using Equation (3).

$t_{\text {opt }, E x}=\left(\frac{1}{\alpha}-1\right) \frac{\dot{W}_{0} t_{\text {tool change }}+E_{\text {cutting edge }}\left(\frac{T}{T_{0}}\right)}{\dot{W}_{0}}$

Equation (20) is alike to equation (8) except that the temperature effect is added. With this process, exergy analysis by adding the temperature values of the energy quality concept can ensure a more environmentally friendly optimization of the machining process.

\section{Procedure of the experimental}

In experimental of this study, DIN 1.2367 steel material was used as workpiece. This material is widely used. Suitable for heat treatment. The lathe where processing tests are performed is the TTC 630 model produced by TEZMAKSAN. The high rigidity of this machine has enabled measurement tests to be performed in a safe environment. The machine has $20 \mathrm{hp}$ and has a maximum rpm of $4000 \mathrm{rpm}$. Values of instantaneous current were measured using calibrated devices on the processing bench. The photo of the measurement is seen in Fig. (Figure) 1.

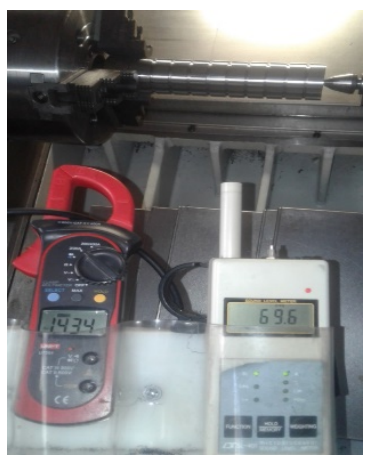

Fig. 1. Measurement of instantaneous current values [14] Taequtec company's 11T04 model DCMT 110408 geometry cutting tools were used for chip removal. This tool is preferred because it is a finishing turning process. It can be seen in Fig. 2.

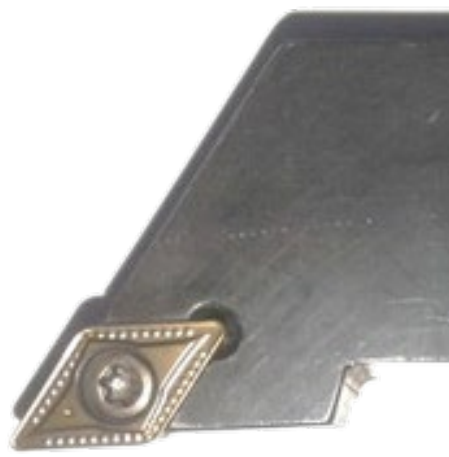

Fig. 2. DCMT 11T04 Cutting Tool [14]

Table 1 shows cutting parameters requested for experimental study.

Table 1. Parameters of Cutting

\begin{tabular}{ll}
\hline Cutting Edge & DCMT 11T04 \\
Cutting Speed (m/min) & $175,200,225$ \\
Feedrate $(\mathrm{mm} / \mathrm{rev})$ & 0.15 \\
Depth of Cut $(\mathrm{mm})$ & $0.06,0.12,0.18$ \\
Diameter of Material $(\mathrm{mm})$ & 50 \\
Length of Material $(\mathrm{mm})$ & 250
\end{tabular}

The energy footprint of the cutting tool is the energy required for tool production. It consists of the energy in the tool material required for production, the energy required for sintering and the energy required for processes such as coating.

\subsection{Surface Wear}

The average flank wear tool life criterion of $0.3 \mathrm{~mm}$ is recommended by the ISO 3685 standard in determining tool life. In this study, flank wear tool life criteria of $0.3 \mathrm{~mm}$ were reached after $35.89,31.40$, and 27.91 minutes, cutting speeds of 175,200 and $225 \mathrm{~m} / \mathrm{min}$, respectively.

\subsection{Exergy Loss Analysis}

Eq. (17) is used to evaluate the exergy loss in dry turning process. The parameters needed to use for this equation are showed in Table 2.

Table 2. Required Parameters for Calculations in the Turning Process

\begin{tabular}{ll}
\hline Machine Idle Power Consumption & $3.594 \times 10^{3} \mathrm{~W}$ \\
Tool Change Time & $120 \mathrm{~s}$ \\
Temperature of Environmental & $25 \mathrm{C}$ \\
Temperature of Heat Source & $36 \mathrm{C}$ \\
\hline
\end{tabular}

\section{Result and Discussions}

The parameters used in the turning process and the values whose properties are given are evaluated by using the above equations and calculating them in excel. Along with the detailed calculations, exergy loss and exergy efficiency having important in turning processes were especially emphasized. Figure 3. indicates the impact of the change in speed of cutting on the exergy loss in the turning process. An increase in cutting speed can reason a fast decrease in exergy loss initially. But, as the speed of cutting rising, the change in exergy loss gets less important. This is because the cutting speed progresses at a more optimal speed over time in dry turning.

Fig. 3. Variation of Exergy Loss effected from cutting speed in dry turning process 


\subsection{Efficiency of Energy}

Equation (21) can be used to show the exergy efficiency of a system [15].

$\varphi=1-\frac{E x_{\text {loss }}}{E x_{\text {in }}+E x_{w, i n}+E x_{Q, i n}}$

Figure 4 illustrates the change in exergy efficiency of the cutting speed during the process.

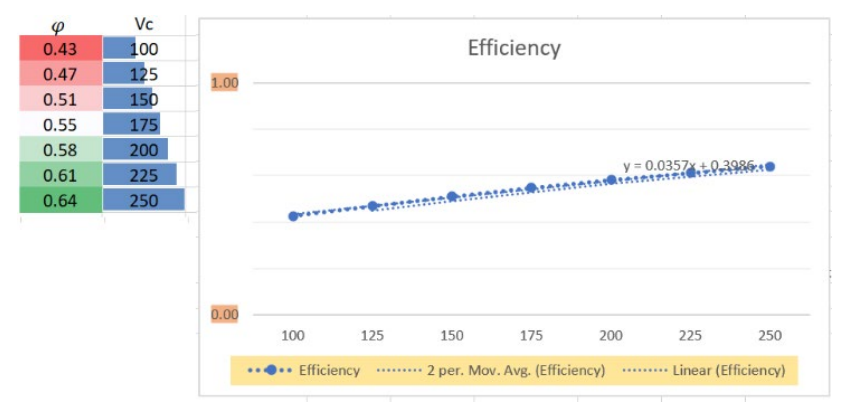

Fig. 4. Change in Efficiency Depending on the Cutting Speed

According to Figure 4, the increase in cutting speed causes a noticeable increase in efficiency. This study proves that the increase in cutting speed causes an increase in exergy efficiency, contrary to Ghandehariun, A. et al., (2015), [4]. Therefore, an increase in the speed of cutting reduces the exergy loss in the process as shown in Fig. 3 and leads to an improved efficiency as in Figure 4.

\section{Conclusions}

Exergy values were obtained by using optimum parameter values in cutting process and the efficiency of the system was questioned in dry turning. Attention was also drawn to exergy losses in the machining process. The study can be a reference especially for energy studies in the manufacturing industry. The study mainly reflected:

$\checkmark \quad$ The change in cutting speed is effective in exergy loss. An increase in the speed of cutting at first leads to a fast decrease in exergy loss. But, as the cutting speed increased, the downward trend in exergy' loss decreased. When the cutting speed reaches an optimum value, this tendency to decrease becomes less significant.

$\checkmark \quad$ An increase in cutting speed causes a logarithmic shot in dry turning process, which reflected the importance of finding optimum values in cutting processes.

$\checkmark \quad$ Another issue that should be considered together with the cutting speed is the optimum cutting time. Optimum cutting time not only reduced energy losses but also positively affected energy efficiency.

Energy and exergy efficiency studies like this study can be studied using other materials (aluminium, different steel materials, bronze etc.) in dry turning processes.

\section{Nomenclature}

$\mathrm{l}$ : Length of cut (m)

Q: Heat transfer between system and surrounding $(J)$

Ex: Exergy (J)

Ex $x_{\text {loss: }}$ Loss of Exergy $(\mathrm{J})$

Ex,Q: Exergy of Thermal ( $\mathrm{J})$

$\mathrm{Ex}_{\text {,w: }}$ : Work Exergy $(\mathrm{J})$

$D_{\text {avg: }}$ Workpiece's average diameter $(\mathrm{m})$

$D_{\mathrm{f}}$ : Workpiece's final diameter (m)

$\mathrm{D}_{\mathrm{i}}$ : Workpiece's initial diameter $(\mathrm{m})$

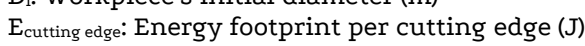

$E_{\text {tool: }}$ Energy footprint of cutting tool (J)

f: Feed rate (mm/rev)

$\mathrm{k}$ : Specific cutting energy value $\left(\mathrm{J} / \mathrm{m}^{3}\right)$

$\mathrm{t}$ : Life of tool (s) tcutting: Cutting time (s)

topt, En: Optimum tool life based on minimum energy consumption ( $J$ )

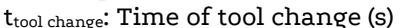

$\mathrm{T}$ : Temperature of heat source $\left({ }^{\circ} \mathrm{C}\right)$

$\mathrm{T}_{\mathrm{o}}$ : Temperature of environmental $\left({ }^{\circ} \mathrm{C}\right)$

$\mathrm{V}_{\mathrm{c}}$ : Cutting speed $(\mathrm{m} / \mathrm{min})$

$\dot{W}_{0}$ : Power consumed by machine modules (W)

$\dot{V}$ : Material removal rate $\left(\mathrm{m}^{3} / \mathrm{s}\right)$

Welec: Electircal energy consumption (W)

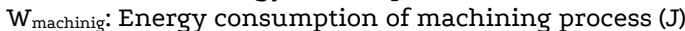

$\mathrm{W}_{\text {setup }}$ : Energy consumption of setup process $(\mathrm{J})$

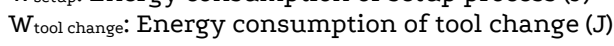

$\varphi$ : Efficiency

\section{Declaration of Conflict of Interests}

The author declares that there is no conflict of interest. He has no known competing financial interests or personal relationships that could have appeared to influence the work reported in this paper.

\section{References}

[1.] Pusavec et al., (2010). Pusavec, F., Krajnik, P. and Kopac, J. "Transitioning to sustainable production - Part I: application on machining technologies", Journal of Cleaner Production, Vol. 18, pp.174-184.

[2.] Cakir, A. K. and B. Sansli, (2020). "Conducting exergy analysis by utilizing condenser waste heat in commercial type split air conditioner: a case study," SN APPLIED SCIENCES, vol.2.

[3.] Rajemi et al. 2009. Rajemi, M.F., Mativenga, P.T., Jaffery, S.I. "Energy and carbon footprint analysis for machining titanium Ti-6Al-4V Alloy". Journal of Machine Engineering 9 (1), 103-112.

[4.] Ghandehariun, A., Nazzal, Y., Kishawy, H. and Al-Arifi, N.S.N. (2015) "Investigation of sustainability in machining processes: exergy analysis of turning operations", Int. J. Exergy, Vol. 17, No. 1, pp.1-16.

[5.] Campatelli, G., (2009). Analysis of the environmental impact for a turning operation of AISI 1040 steel. (IPROMS2009- Innovative Production Machines and Systems.

[6.] Goldwitz, (2002). J. Goldwitz, "Productivity Gains and Environmental Impact of Turning Tools", Bachelor of Science Thesis in Mechanical Engineering, Massachusetts Institute of Technology, Cambridge, Massachusetts.

[7.] Gutowski, (2010). Gutowski, T. 'The efficiency and eco-efficiency of manufacturing', International Journal of Nanomanufacturing, Vol. 6, pp.38-45.

[8.] Kalpakjian, S., Schmid, S.R., 2006. Manufacturing Engineering and Technology. Pearson Prentice Hall, Singapore.

[9.] Hinduja and Sandiford, (2004). Hinduja, S. and Sandiford, D. "An optimum two-tool solution for milling $21 / 2 \mathrm{D}$ features from technological and geometric viewpoints", CIRP Annals Manufacturing Technology, Vol. 53, pp.77-80.

[10.] Rajemi at al., (2010). Rajemi, M., Mativenga, P. and Aramcharoen, A. 'Sustainable machining: selection of optimum turning conditions based on minimum energy considerations', Journal of Cleaner Production, Vol. 18, pp.1059-1065.

[11.] Taylor, J., 1977. "The estimation of tool life equation by extrapolation". Proceeding of the 18th International Machine Tool Design and Research Conference, pp. 379-3385.

[12.] Moran and Shapiro, (2008). Moran, M.J. and Shapiro, H.N "Fundamentals of Engineering Thermodynamics", Wiley, Hoboken, NJ.

[13.] Gutowski et al. (2006). Gutowski, T., Dahmus, J. and Thiriez, A 'Electrical energy requirements for manufacturing processes', 13th CIRP International Conference on Life Cycle Engineering, Leuven, Belgium, 2006, Lueven, Belgium, pp.1-5.

[14.] Cakir, A.K. Analysis of Surface Roughness, Sound Level and Machine Current in the Turning of Hardened AISI S1 Steel. Trans Indian Inst Met (2021). https://doi.org/10.1007/s12666-021-02196-8.

[15.] Dincer and Rosen, 2013. Exergy: Energy, Environment, and Sustainable Development, Elsevier, Oxford, UK; Amsterdam, Netherlands; Waltham, MA.

\section{How to Cite This Article}

Cakir, A.K, Investigation of the Exergy Analysis and Efficiency in the Turning of DIN 1.2367 Material, Brilliant Engineering, 4 (2021), 1-4. https://doi.org/10.36937/ben.2021.004.001 